\title{
The Construction of the Teaching Model for PE under the Horizon of Sunshine Sports Movement
}

\author{
Min Li \\ Jiangxi Science and Technology Normal University, NanChang 330013, China \\ paperiset@163.com
}

Keywords: University sports culture, sunshine sports, construction.

\begin{abstract}
University sports culture is a kind of unique social cultural phenomenon which has a profound connotation, and it is an important part of university culture. Through the method of literature material, logic analysis and other analysis, the construction of university sports culture under the background of sunshine sports has been explored combined university culture in this paper. It mainly focus on three aspects of the university sports culture, that's, material culture, system culture and spirit culture, and the construction of them has been positively explored.
\end{abstract}

\section{Introduction}

As a cradle of the motherland, university usually cultivates talents for the society. The construction of university culture is also more and more attracting wide attention by the social from all walks of life. The construction of the sunshine sports culture of university, it not only directly plays the role of sports culture and university culture in the process of implementing quality education to improve the quality of college students. Meanwhile, it indirectly promotes the elementary and middle schools education for all-around development work from another aspect. As an important part of university culture, college sports culture has injected a new vigor for the university with the smoothly launching of sunshine sports in national. To carry out the sunshine sports, we need to understand from the meaning of life, in accordance with the law of life to develop the education. At the same time, we should make a scientific orientation from the goal setting, the content setting, the process setting, effect evaluation to comply with the rules in the development of life and realize the transformation of the life's structure and function to promote human's life significance [1]. The life of sunshine sports contains and pays close attention to life quality and life experience, and it focus on promoting the life itself. Based on the background of sunshine sports, a depth empirical research on China's university sports culture is made in this paper, and the research paradigm of China's university sports culture is built in order to promote the development of Chinese college students' education.

\section{The Relationship of Sunshine Sports and College Sports Culture}

The Sunshine Sports Has Enriched The University Sports Culture. Under the background of the whole university campus culture and atmosphere, University sports culture is a kind of group culture that it is in the university campus space, with students and teachers to participate as the main body, by means of physical exercises, using the variety of physical exercise project as the main content with its unique form and the feature of times. The sunlight sports is proposed when the modernization construction of our country has entered a certain period and the level of modernization education has made a considerable development. The goal of school is to cultivate high-quality and comprehensive talents and change the education idea. In the principle of people-oriented, university sports culture is an important measure to comprehensively improve the connotation and hierarchy of education and the quality of the all-round development of education.

The goal of carrying out the sunshine sports is to make various levels of schools form a rich campus sports culture, make the students go into the nature and walk in the sun, cultivate interest in physical exercise and develop the exercise habit through the promoting function of sunlight sports. Then it can form a campus sports culture of growing up in a happy and healthy life. And the new sports concept has been into the campus sports culture, which makes the campus sports culture be 
more rich. The rich campus sports culture creates a good atmosphere for students to spontaneously exercise and lays a good foundation for the lifelong sports. Lifelong sports idea is the best annotation of sunshine sports[2].

The Sunshine Sports Guides the Development of the University Sports Culture. The formation and development of sports culture is based on the students' love for sports and participation. It is the spiritual environment and cultural atmosphere which has a common values and code of conduct formed through taking the student as the main body, the campus cultural activities as the carrier. So in the lead of the sunshine sports, campus sports culture is the important guarantee of the design and implementation of campus sports activities. Through constant values and culture atmosphere, schools and teachers can teach students the sports thoughts and ideas. It also can stimulate students' physical education learning motivation, improve students' physical education learning enthusiasm and strengthen students' sports consciousness. All these can promote students to actively exercise. Meanwhile it can better finish the goal of school sports education and continue to influence and guide the students to participate in sports activities.

\section{Sunlight Sports Under the Background of University Sports Culture Construction}

Comment on Pros and Cons of College Sports System Culture Construction. University sports material culture include the sports venues, sports stadiums and other material resources. University sports activities mainly carried out by sports site and equipment. But due to the fiery carry out of the sunshine sports, college students' enthusiasm to participate in sports activities is rising, it will facing with that university sports material resources shortage[3]. Although schools are trying to meet the students' increase enthusiasm in sports, but by funding and other issues, the construction of sports grounds and stadiums have been not strengthen. As shown in table 1.

Table 1 The number of students and stadiums acreage statistics in2013,2014 [1,2,3,4]

\begin{tabular}{ccc}
\hline & 2013 & 2014 \\
\hline The total number of students (ten thousand) & 3011.2 & 3031.2 \\
The total acreage of Stadiums $\left(\mathrm{m}^{2}\right)$ & 1651035 & 1751035 \\
The sports venues acreage per capita $\left(\mathrm{m}^{2} /\right.$ one people $)$ & 9.2 & 9.7 \\
\hline
\end{tabular}

Table 1 reflects the contrast of students stadiums per capita situation in collage, although it is increasing every year, but the number of students stadiums per capita is still inadequate at present, the movement we can do is quite limited in 9 square meters of space, of course, we have to take the situation of collage into account. China's large population and college enrollment make the overcrowded university stadium become more and more crowded. As it can be seen from the data, our universities are still struggling in expansion stadiums, but at the same time, some problems also are exposed.

Rich Material Culture and Strengthen the Surface Layer Construction of the University Sports Culture. University sports material culture is materialized sports culture formation and physical condition of university teach, scientific research, social services and so on. It is the material carrier of college sports spiritual culture and sports institutional culture. University sports material culture is created by university teachers and students, generations of teachers and students using their wisdom, passion and sweat created the college sports material culture with unique charm. Material culture is tangible, but its educational role is invisible, it always affects teachers and students in the campus, make students and teachers feel the presence of school sport culture all the time and influence their sport values[4].

The arrival of sunshine sports, marks that school sports is moving forward in the direction personality, physical collage education pay more attention on humane education model. However, to a large extent, traditional sports management system limit the development of the students physical exercise in this direction, it is difficult to adapt to the new era sports university. The current organization of sports teaching and activities are staying in form, it does not mobilize interest and enthusiasm of students to participate in physical exercise fundamental. Influence by the traditional 
ideas and culture, examination remains an important means and measures to evaluate students' academic achievement.

Sound System Culture and Strengthen the Middle Construction of the University Sports Culture. Student sports associations become community which has significant influence and cohesion in the college. As the important positions for student self-improvement and self-development and the important supplement form for first class .University student sports associations already showing vitality and existence. Student sports associations play an important role in students' growth process.

From 2007 to 2009, for students, the Ministry of Education and the State Sports General Administration released the initiative of Sunshine Sports winter long-distance running events three times consecutive. And the targets for college students are marathon 2,000 meters every day, winter marathon $240 \mathrm{~km}$ totally .

Comment on Pros and Cons of University Sports Spiritual and Cultural Construction. Spirit culture of university sports culture is the invisible level of college sports culture, at the core, whether a university sports culture construction success largely depends on its spiritual culture construction. Though university sports spiritual culture has been got more and more attention at present and its construction has achieved great progress, but university sports culture construction among the invisible cultural spirit is still the most weak link, problems mainly concentrated in the cultivation of sports consciousness and sports spirit.

As the rich diversity of university sports culture activities, Students' choice of sports activities have greater autonomy, which also points out that the aims of University Physical Culture is to train university students' interest in sports. Interest is the largest intrinsic motivation for college students' participation in sports activities so that students can feel the charm of sport spirit. However, college students' understanding of sport is still relatively lacking, thus generating a lot of misunderstanding on sport. Some people think that physical activity can affect students achievement, and it is not conducive to the development of students. With the progress of society, although everyone improve understanding of sports, but people also can't realize inner sports spirit and lack of physical exercise consciousness, it also brings a series of social drawbacks.

In addition, physical education is easy to overlook the train of sport spirit . Education should pay more attention on training sport spirit. Currently, sports teaching lack sportsmanship and sport spirit. Sports results can not represent the level of a university sports culture construction, it can only reflect the university's athletic level. Athletic athlete can only represent a small part of university students, but most students are just sports participants. Although college students now increasingly focused on the spirit of sports culture, but university education system make them unknown for what to do, they can not well receive spirit sports training from the sports teaching .

Refine Spiritual Culture and Strengthen the Construction of University Sport Culture. thought the effective and reasonable movement and using motion form which collage students can accept, sunshine sport can increase the enthusiasm of collage students participate in sports, promote the students' sport consciousness and sport spirited in the participating process.at the same time, sport can make students pull out form the intense study.

Sunshine sports meet university students learning enthusiasm for sport, improve the overall atmosphere of the university sports culture and enrich the university culture. Students can choose a variety of sports activities, which help develop the enthusiastic of college students to participate in sports activities[5]. Provide a suitable space for the development of sports skills and reasonable conditions for the construction of university sports culture.

With a positive and healthy exercise form, sunshine sport integrated into university sports culture life. Enthusiastic of college students to participate in sports is increasing. Meanwhile, Sunshine sports also convey a sunshine sport form .Sunshine sports is not just a sport, but reflects the university students youth, vitality and positive spirit realm.

Enhance Sport Awareness of College Students by Sunshine Sports. Awareness of physical exercise is people's overall understanding and views for sport. For students, it means the activities they decide to conduct in the process of participation in sports activities, according to personal 
understanding of sports and taking the correct and effective way personally thinking. The current situation is: students are subject to constraints and impact by heir cultural enrichment, ethics, sports-based, their quality, their cognitive ability, family, school, social and other factors, which Resulting in students sports consciousness, the concept of focus on study, dessertspoon sport dominate, students' participation sense weakly. Students ignored the importance of physical activity in life, Learning occupy their time which should be participated in sports, and weak their awareness of physical exercise.

In order to increase interesting of students' participate in physical exercise, the reform of college sports curriculum is constantly updated, but it does not consider the sport training awareness which formed before college freshmen enrolled, and these conscious are often play a leading role to the behavior of college students .So the sunshine sport should pay more attention to the change and improvement of students physical exercise awareness. So that students voluntarily to the playground, to the sunshine, participate in sports, form good exercise habits and improve physical health effectively .

Thus, even thought the goal of sunshine sport is Fight for excellent and strong body, but the ultimate goal is to guide students change their sports training consciousness, actively participate in physical exercise and lifelong benefits.

\section{Conclusion}

Sunshine sports represents not only a sport, a kind of form, it also represents the youth, vigor, and a vibrant campus. The sunshine sports plays a very important role in the process of the college sports culture's construction.

Studies show that college sports culture includes three basic levels which are material culture, system culture and spirit culture. The current situation of university sports culture's construction reflects the unbalanced development of sports material culture construction in the aspect of material culture, the lose of the concept of the team ship hardware facilities construction and the un-advance of sports facilities management. In the construction of institutional culture, it also exists the problem that college sports system is not perfect and the traditional management system is difficult to meet the needs of university sports culture. The deviation on sports awareness leads to that the sports consciousness is not strong and the teaching form is single. The neglect of the cultivation of sports spirit is also exposed the insufficiency of university sports culture spirit.

\section{References}

[1]Harman, K. Merging divergent campus cultures into coherent educational communities: Challenges for Higher Education Leaders, Vol. 44 (2002) No.3, p.91-114.

[2] Ferguson, K.\&S. Masur \& L. Olson \&J. Ramirez\& E. Robyn: Enhancing the Culture of Research Ethics on University Campuses, Vol. 5 (2007) No.3, p.189-193.

[3] Iannone, C: Uncultured Campus Culture, Vol. 23 (2010) No.4, p.152-155.

[4] Ehlers, U.\&D: Reichenberg. Changing Culture in Higher Education(Peking University Press, Chinese, 2010).

[5]Zhang Sun: Universities Sport Mode System Design and Implementation--Facing reflection of

Sunshine Sport, Vol. 14 (2009) No.5, p.66-67. 